\title{
ON PROXIMAL CONTRACTIONS VIA IMPLICIT RELATIONS AND BEST PROXIMITY POINTS
}

\author{
PRATIKSHAN MONDAL, HIRANMOY GARAI, AND LAKSHMI KANTA DEY \\ Received 08 September, 2020
}

\begin{abstract}
In this paper, we employ two types of implicit relations to define some new kind of proximal contractions and study about their best proximity points. More precisely, we use two class of functions $\mathcal{A}$ and $\mathcal{A}^{\prime}$ to explore proximal $\mathcal{A}, \mathcal{A}^{\prime}$-contractions of first and second kind and strong proximal $\mathcal{A}, \mathcal{A}^{\prime}$-contractions. We investigate the existence of best proximity points results of the same. It is worth mentioning that the well-known results of Sadiq Basha [J. Approx. Theory, 2011] on proximal contractions are the special cases of our obtained results. We authenticate our results by suitable examples. Finally, we point out some areas where our obtained results can be applied.
\end{abstract}

2010 Mathematics Subject Classification: 47H10; 54H25

Keywords: Best proximity point, proximal contraction, strong proximal contraction, approximative compactness.

\section{INTRODUCTION}

Best proximity point theory deals with a natural generalization of fixed point theory by routing the method of computing an optimal approximate solution to the equation $S x=x$, where $S: G \rightarrow H$ is a non-self mapping, $G, H$ being two disjoint subsets of a metric space $(M, d)$. Since for $x \in G$, we always have $d(x, S x) \geq \operatorname{dist}(G, H)$, where $\operatorname{dist}(G, H)=\inf \{d(x, y): x \in G, y \in H\}$, it follows that an element $x \in G$ will be an approximate optimal solution of $S x=x$ if $d(x, S x)=\operatorname{dist}(G, H)$. Such a point ' $x$ ' is known as a best proximity point of $S$, and the branch of mathematics dealing with best proximity points is known as the best proximity point theory. There are numerous articles that analyze several kinds of contractions for the existence of best proximity point(s) for single-valued as well as multivalued mappings. Interested readers may consult with the papers $[3,4,9,13,15,18,19]$ for single-valued mappings and $[2,11,12,20,22]$ for multivalued mappings.

The study of the best proximity point theory by using different contractions had been enriched in 2011 with a new kind of contraction by Sadiq Basha [17]. In [17],

The second author was supported by CSIR, New Delhi, INDIA (Award Number: 09/973(0018)/2017-EMR-I. 
he came with some new kind of contractions such as proximal contractions of the first kind, proximal contractions of the second kind, strong proximal contractions of the first kind.

Definition 1. ([17, p. 1774, Definitions 2.2-2.4]). Let $(M, d)$ be a metric space and $G, H$ two non-empty subsets of $M$. A mapping $S: G \rightarrow H$ is said to be a

(i) proximal contraction of the first kind if there exists $\alpha \in[0,1)$ satisfying

$$
\left.\begin{array}{l}
d\left(u_{1}, S x_{1}\right)=\operatorname{dist}(G, H) \\
d\left(u_{2}, S x_{2}\right)=\operatorname{dist}(G, H)
\end{array}\right\} \Longrightarrow d\left(u_{1}, u_{2}\right) \leq \alpha d\left(x_{1}, x_{2}\right)
$$

for all $u_{1}, u_{2}, x_{1}, x_{2} \in G$,

(ii) proximal contraction of the second kind if there exists $\alpha \in[0,1)$ satisfying

$$
\left.\begin{array}{l}
d\left(u_{1}, S x_{1}\right)=\operatorname{dist}(G, H) \\
d\left(u_{2}, S x_{2}\right)=\operatorname{dist}(G, H)
\end{array}\right\} \Longrightarrow d\left(S u_{1}, S u_{2}\right) \leq \alpha d\left(S x_{1}, S x_{2}\right)
$$

for all $u_{1}, u_{2}, x_{1}, x_{2} \in G$,

(iii) strong proximal contraction of the first kind if there exists $\alpha \in[0,1)$ such that for all $u_{1}, u_{2}, x_{1}, x_{2} \in G$ and for all $\gamma \in[1,2)$

$$
\left.\begin{array}{l}
d\left(u_{1}, S x_{1}\right) \leq \gamma \operatorname{dist}(G, H) \\
d\left(u_{2}, S x_{2}\right) \leq \gamma \operatorname{dist}(G, H)
\end{array}\right\} \Longrightarrow d\left(u_{1}, u_{2}\right) \leq \alpha d\left(x_{1}, x_{2}\right)+(\gamma-1) \operatorname{dist}(G, H) .
$$

In the above definitions of proximal contractions, we see that the definitions involves the displacement $d\left(x_{1}, x_{2}\right)$ only. It is known that for two points $x_{1}, x_{2}$, the other displacements are $d\left(S x_{1}, x_{1}\right), d\left(S x_{2}, x_{2}\right), d\left(S x_{1}, x_{2}\right)$ and $d\left(S x_{2}, x_{1}\right)$, and there are a plenty number of contractions which involves these displacements, and these contractions play a crucial role in the theory of fixed point and best proximity point. If we compare Definition 2 with some usual well-known contractions, then one can notice that $u_{1}, u_{2}$ play the roles of $S x_{1}, S x_{2}$ in Definition 2. So if someone requires to extend the proximal contractions by using the displacements $d\left(S x_{1}, x_{1}\right), d\left(S x_{2}, x_{2}\right), d\left(S x_{1}, x_{2}\right)$, $d\left(S x_{2}, x_{1}\right)$, then one has to work with $d\left(u_{1}, x_{1}\right),\left(u_{2}, x_{2}\right), d\left(u_{1}, x_{2}\right), d\left(u_{2}, x_{1}\right)$ respectively. So it will be impressive works if the concepts of proximal contractions can be enlarged by involving the displacements $d\left(u_{1}, x_{1}\right),\left(u_{2}, x_{2}\right), d\left(u_{1}, x_{2}\right), d\left(u_{2}, x_{1}\right)$.

Motivated by this fact, in the current paper, we broaden the proximal contractions by associating all the five displacements $d\left(x_{1}, x_{2}\right), d\left(u_{1}, x_{1}\right), d\left(u_{2}, x_{2}\right), d\left(u_{1}, x_{2}\right)$ and $d\left(u_{2}, x_{1}\right)$. To continue this, we introduce proximal $\mathcal{A}$-contractions which involve $d\left(x_{1}, x_{2}\right), d\left(u_{1}, x_{1}\right)$ and $d\left(u_{2}, x_{2}\right)$; and proximal $\mathcal{A}^{\prime}$-contractions which involve $d\left(x_{1}\right.$, $\left.x_{2}\right), d\left(u_{1}, x_{2}\right)$ and $d\left(u_{2}, x_{1}\right)$. More specifically, we define proximal $\mathcal{A}$-contractions of first and second kind; proximal $\mathfrak{A}^{\prime}$-contractions of first and second kind; strong proximal $\mathcal{A}$-contractions and strong proximal $\mathcal{A}^{\prime}$-contractions. After this, we study on adequate sufficient conditions to ensure the existence of best proximity point(s) of the above-mentioned contractions, and access the required adequate sufficient conditions which will be presented in next section. Along with this, we give a number of examples to support the validity of our proven results. 
Throughout this paper, $\mathcal{A}$ and $\mathcal{A}^{\prime}$ will contain all functions $f: \mathbb{R}_{+}^{3} \rightarrow \mathbb{R}$ having the properties $\left(\mathcal{A}_{1}\right)-\left(\mathcal{A}_{2}\right)$ and $\left(\mathcal{A}_{1}^{\prime}\right)-\left(\mathcal{A}_{3}^{\prime}\right)$ respectively, where

$\left(\mathcal{A}_{1}\right)$ there exists $k \in[0,1)$ such that if $r \leq f(s, s, r)$ or $r \leq f(r, s, s)$, then $r \leq k s$ for all $r, s \in \mathbb{R}_{+}$

$\left(\mathcal{A}_{2}\right)$ there exists $\alpha \in[0,1)$ such that $f(r, 0,0) \leq \alpha r$; and

$\left(\mathcal{A}_{1}^{\prime}\right)$ there exists $k \in[0,1)$ such that if $r \leq f(s, 0, r+s)$, then $r \leq k s$ for all $r, s \in \mathbb{R}_{+}$;

$\left(\mathcal{A}_{2}^{\prime}\right)$ if $t \leq t_{1}$, then $f(r, s, t) \leq f\left(r, s, t_{1}\right)$ for all $r, s, t, t_{1} \in \mathbb{R}_{+}$;

$\left(\mathcal{A}_{3}^{\prime}\right)$ if $r \leq f(r, r, r)$, then $r=0$.

For examples and properties of such collections of mappings, we refer the readers to $[1,7,14]$.

\section{MAIN RESULTS}

Throughout this section, $(M, d)$ will denote a metric space and $G, H$ will denote two non-empty subsets of $M$, and $G_{0}, H_{0}$ will denote the following:

$$
\begin{aligned}
& G_{0}=\{x \in G: d(x, y)=\operatorname{dist}(G, H) \text { for some } y \in H\} \\
& H_{0}=\{y \in H: d(x, y)=\operatorname{dist}(G, H) \text { for some } x \in G\} .
\end{aligned}
$$

First, we define proximal $\mathcal{A}, \mathcal{A}^{\prime}$-contractions of the first kind in the following way:

Definition 2. A mapping $S: G \rightarrow H$ is said to be a

(i) proximal $\mathcal{A}$-contraction of the first kind if there exists an $f \in \mathcal{A}$ satisfying

$$
\begin{aligned}
& \left.\begin{array}{l}
d\left(u_{1}, S x_{1}\right)=\operatorname{dist}(G, H) \\
d\left(u_{2}, S x_{2}\right)=\operatorname{dist}(G, H)
\end{array}\right\} \Longrightarrow d\left(u_{1}, u_{2}\right) \leq f\left(d\left(x_{1}, x_{2}\right), d\left(u_{1}, x_{1}\right), d\left(u_{2}, x_{2}\right)\right) \\
& \quad \text { for all } u_{1}, u_{2}, x_{1}, x_{2} \in G
\end{aligned}
$$

(ii) proximal $\mathcal{A}^{\prime}$-contraction of the first kind if there exists an $f \in \mathcal{A}^{\prime}$ satisfying

$$
\begin{aligned}
& \left.\begin{array}{l}
d\left(u_{1}, S x_{1}\right)=\operatorname{dist}(G, H) \\
d\left(u_{2}, S x_{2}\right)=\operatorname{dist}(G, H)
\end{array}\right\} \Longrightarrow d\left(u_{1}, u_{2}\right) \leq f\left(d\left(x_{1}, x_{2}\right), d\left(u_{1}, x_{2}\right), d\left(u_{2}, x_{1}\right)\right) \\
& \quad \text { for all } u_{1}, u_{2}, x_{1}, x_{2} \in G .
\end{aligned}
$$

Our first two results regarding the existence of best proximity point(s) of the above two proximal contractions are as follows:

Theorem 1. Suppose that $(M, d)$ is complete, $G, H$ are closed and $G_{0} \neq \varnothing$. Let $S: G \rightarrow H$ be a continuous proximal $\mathcal{A}$-contraction of the first kind such that $S\left(G_{0}\right)$ resides in $H_{0}$. Then $S$ has a unique best proximity point.

Proof. Since $G_{0}$ is non-empty, we choose an element $u_{0} \in G$. Then $S u_{0} \in S\left(G_{0}\right) \subset$ $H_{0}$. Then we find an element $u_{1} \in G_{0}$ such that $d\left(u_{1}, S u_{0}\right)=\operatorname{dist}(G, H)$. Similarly, $S u_{1} \in H_{0}$ and in the same way we find an element $u_{2} \in G_{0}$ such that $d\left(u_{2}, S u_{1}\right)=$ 
$\operatorname{dist}(G, H)$. Continuing this process, we arrive at a sequence $\left\{u_{n}\right\}$ of elements of $G_{0}$ such that

$$
d\left(u_{n+1}, S u_{n}\right)=\operatorname{dist}(G, H) \text { for all } n \in \mathbb{N} .
$$

Now note that

$$
d\left(u_{n}, S u_{n-1}\right)=\operatorname{dist}(G, H)
$$

and

$$
d\left(u_{n+1}, S u_{n}\right)=\operatorname{dist}(G, H)
$$

for all $n \in \mathbb{N}$. Since $S$ is a proximal $\mathcal{A}$-contraction of the first kind, there exists an $f \in \mathcal{A}$ such that

$$
d\left(u_{n}, u_{n+1}\right) \leq f\left(d\left(u_{n-1}, u_{n}\right), d\left(u_{n}, u_{n-1}\right), d\left(u_{n+1}, u_{n}\right)\right) .
$$

So there exists a $k \in[0,1)$ such that

$$
d\left(u_{n}, u_{n+1}\right) \leq k d\left(u_{n-1}, u_{n}\right)
$$

for all $n \in \mathbb{N}$ which, in fact, implies that

$$
d\left(u_{n}, u_{n+1}\right) \leq k^{n} d\left(u_{1}, u_{0}\right) .
$$

Now for any $m, n \in \mathbb{N}$, we have

$$
\begin{aligned}
d\left(u_{m+n}, u_{n}\right) & \leq d\left(u_{m+n}, u_{m+n-1}\right)+d\left(u_{m+n-1}, u_{m+n-2}\right)+\cdots+d\left(u_{n+1}, u_{n}\right) \\
& \leq\left(k^{m+n-1}+k^{m+n-2}+\cdots+k^{n}\right) d\left(u_{1}, u_{0}\right) \\
& =k^{n} \frac{1-k^{m}}{1-k} d\left(u_{1}, u_{0}\right) \longrightarrow 0 \text { as } m, n \rightarrow \infty .
\end{aligned}
$$

Therefore, $\left\{u_{n}\right\}$ is a Cauchy sequence in $G$. Being a closed subset of a complete metric space $(M, d), G$ supplies an element $u$ such that $u_{n} \longrightarrow u$ as $n \rightarrow \infty$. Then, by continuity of $S$, we get $S u_{n} \rightarrow S u$ as $n \rightarrow \infty$ and consequently $d\left(u_{n+1}, S u_{n}\right) \rightarrow d(u, S u)$. Now $d\left(u_{n+1}, S u_{n}\right)=\operatorname{dist}(G, H)$ for all $n \in \mathbb{N}$, confirms that $d(u, S u)=\operatorname{dist}(G, H)$ which shows that $u$ is a best proximity point of $S$.

Let $u^{*} \in G$ be such that $d\left(u^{*}, S u^{*}\right)=\operatorname{dist}(G, H)$. Then we have

$$
d\left(u, u^{*}\right) \leq f\left(\left(d\left(u, u^{*}\right), d(u, u), d\left(u^{*}, u^{*}\right)\right)=f\left(d\left(u, u^{*}\right), 0,0\right)\right.
$$

which implies that

$$
d\left(u, u^{*}\right) \leq k \cdot 0=0 .
$$

Hence $u=u^{*}$ and the theorem is proved.

Theorem 2. Suppose that $(M, d)$ is complete, $G, H$ are closed and $G_{0} \neq \varnothing$. Let $S: G \rightarrow H$ be a continuous proximal $\mathcal{A}^{\prime}$-contraction of the first kind such that $S\left(G_{0}\right)$ resides in $H_{0}$. Then $S$ has a unique best proximity point in $G$. 
Proof. We consider a sequence $\left\{u_{n}\right\}$ of elements of $G_{0}$, defined as in Theorem 1, such that

$$
d\left(u_{n+1}, S u_{n}\right)=\operatorname{dist}(G, H) \text { for all } n \in \mathbb{N} .
$$

Now note that

$$
d\left(u_{n}, S u_{n-1}\right)=\operatorname{dist}(G, H)
$$

and

for all $n \in \mathbb{N}$.

$$
d\left(u_{n+1}, S u_{n}\right)=\operatorname{dist}(G, H)
$$

Since $S$ is a proximal $\mathcal{A}^{\prime}$-contraction of the first kind, there exists an $f \in \mathcal{A}^{\prime}$ such that

$$
\begin{aligned}
d\left(u_{n}, u_{n+1}\right) & \leq f\left(d\left(u_{n-1}, u_{n}\right), d\left(u_{n}, u_{n}\right), d\left(u_{n+1}, u_{n-1}\right)\right) \\
& \leq f\left(d\left(u_{n-1}, u_{n}\right), 0, d\left(u_{n+1}, u_{n}\right)+d\left(u_{n}, u_{n-1}\right)\right) .
\end{aligned}
$$

So there exists a $k \in[0,1)$ such that

$$
d\left(u_{n}, u_{n+1}\right) \leq k d\left(u_{n-1}, u_{n}\right)
$$

for all $n \in \mathbb{N}$. Proceeding as in Theorem 1 , we can show that $\left\{u_{n}\right\}$ is a Cauchy sequence in $G$. Since $G$ is a closed subset of the complete metric space $(M, d)$, $u_{n} \longrightarrow u$ as $n \rightarrow \infty$ for some $u \in G$. That $u$ is a best proximity point of $S$ follows by the similar arguments as in Theorem 1.

Let $u^{*} \in G$ be such that $d\left(u^{*}, S u^{*}\right)=\operatorname{dist}(G, H)$. Since $S$ is a proximal $\mathcal{A}^{\prime}$-contraction of the first kind, we have

$$
d\left(u, u^{*}\right) \leq f\left(d\left(u, u^{*}\right), d\left(u^{*}, u\right), d\left(u, u^{*}\right)\right)
$$

which implies that

$$
d\left(u, u^{*}\right)=0 .
$$

Hence $u=u^{*}$ and the proof is complete.

Next, we give the following supporting examples:

Example 1. We take $M=\mathbb{R}, d$ as the usual metric and choose $G=[2, \infty), H=$ $(-\infty,-1]$. Also we take $f \in \mathcal{A}$ defined by $f(r, s, t)=\frac{3}{4} \max \{r, s, t\}$ and define $S$ : $G \rightarrow H$ by $S x=\frac{2-3 x}{4}$ for all $x \in G$.

Let $u_{1}, u_{2}, x_{1}, x_{2} \in G$ be such that $d\left(u_{1}, S x_{1}\right)=\operatorname{dist}(G, H)$ and $d\left(u_{2}, S x_{2}\right)=\operatorname{dist}(G, H)$. Then

$$
4 u_{1}+3 x_{1}=14 \text { and } 4 u_{2}+3 x_{2}=14 .
$$

Now,

$$
\begin{aligned}
d\left(u_{1}, u_{2}\right) & =\left|u_{1}-u_{2}\right|=\left|\frac{14-3 x_{1}}{4}-\frac{14-3 x_{2}}{4}\right| \\
& =\frac{3}{4}\left|x_{1}-x_{2}\right|=\frac{3}{4} d\left(x_{1}, x_{2}\right),
\end{aligned}
$$


which yields that

$$
d\left(u_{1}, u_{2}\right) \leq \frac{3}{4} f\left(d\left(x_{1}, x_{2}\right), d\left(u_{1}, x_{1}\right), d\left(u_{2}, x_{2}\right)\right) .
$$

Therefore, $S$ is a proximal $\mathcal{A}$-contraction of first kind. So by Theorem $1, S$ has a unique best proximity point, viz., $u=2$.

Example 2. We choose $M=\mathbb{R}, d$ as the usual metric; $G=[6,7], H=[2,3]$; $f(r, s, t)=\frac{49}{50} \max \{s, t\}$ and define $S: G \rightarrow H$ be defined by $S x=9-x$ for all $x \in G$. Let $u_{1}, u_{2}, x_{1}, x_{2} \in G$ be such that $d\left(u_{1}, S x_{1}\right)=\operatorname{dist}(G, H)$ and $d\left(u_{2}, S x_{2}\right)=\operatorname{dist}(G, H)$. Then

$$
u_{1}+x_{1}=12 \text { and } u_{2}+x_{2}=12 .
$$

Without loss of generality, let us suppose that $x_{1} \geq x_{2}$. Then

$$
d\left(u_{1}, u_{2}\right)=\left|u_{1}-u_{2}\right|=\left|12-x_{1}-12+x_{2}\right|=x_{1}-x_{2} .
$$

Also,

$$
d\left(u_{1}, x_{1}\right)=12-2 x_{1} \text { and } d\left(u_{2}, x_{2}\right)=12-2 x_{2} .
$$

Now,

$$
\begin{aligned}
f\left(d\left(x_{1}, x_{2}\right), d\left(u_{1}, x_{1}\right), d\left(u_{2}, x_{2}\right)\right) \\
=\frac{49}{50} \max \left\{x_{1}-x_{2}, 2 x_{1}-12,2 x_{2}-12\right\} \\
=\frac{49}{50}\left(2 x_{1}-12\right)\left[\because x_{1} \geq x_{2}, \text { so, } 2 x_{1}-12 \geq 2 x_{2}-12\right] .
\end{aligned}
$$

Therefore,

$$
d\left(u_{1}, u_{2}\right) \leq f\left(d\left(x_{1}, x_{2}\right), d\left(u_{1}, x_{1}\right), d\left(u_{2}, x_{2}\right)\right)
$$

which shows that $S$ is a proximal $\mathcal{A}$-contraction of first kind. So by Theorem $1, S$ possesses a unique best proximity point, viz., $u=6$.

Example 3. We choose $(M, d)$ as the usual metric space $(\mathbb{R}, d)$ and $G=[3,5]$, $H=[0,1]$. We take $f \in \mathcal{A}^{\prime}$ as $f(r, s, t)=\frac{1}{3}(s+t)$ and consider the mapping $S: G \rightarrow H$ defined by

$$
S x= \begin{cases}1 & \text { if } x \in[3,4] \\ 5-x & \text { if } x \in[4,5] .\end{cases}
$$

Let $u_{1}, u_{2}, x_{1}, x_{2} \in G$ be such that $d\left(u_{1}, S x_{1}\right)=\operatorname{dist}(G, H)=d\left(u_{2}, S x_{2}\right)$. We now consider the following cases:

Case 1: Let $x_{1}, x_{2} \in[3,4]$. Then

$$
\left|u_{1}-1\right|=2 \Longrightarrow u_{1}=3 .
$$

Similarly, $u_{2}=3$. So, it is obvious that

$$
d\left(u_{1}, u_{2}\right) \leq f\left(d\left(x_{1}, x_{2}\right), d\left(u_{1}, x_{2}\right), d\left(u_{2}, x_{1}\right)\right) .
$$


Case 2: Let $x_{1}, x_{2} \in[4,5]$. Then

$$
\begin{aligned}
\left|u_{1}-\left(5-x_{1}\right)\right|=2 & \Longrightarrow\left|u_{1}+x_{1}-5\right|=2 \\
& \Longrightarrow u_{1}+x_{1}=7 .
\end{aligned}
$$

Similarly, $u_{2}+x_{2}=7$. Therefore, $d\left(u_{1}, u_{2}\right)=\left|u_{1}-u_{2}\right|=\left|x_{1}-x_{2}\right|$. Without loss of generality, we assume that $x_{1} \geq x_{2}$. Again,

$$
d\left(u_{1}, x_{2}\right)=\left|u_{1}-x_{2}\right|=\left|7-x_{1}-x_{2}\right|=x_{1}+x_{2}-7 .
$$

Similarly, $d\left(u_{2}, x_{1}\right)=x_{1}+x_{2}-7$. Therefore,

$$
\begin{aligned}
3 d\left(u_{1}, u_{2}\right) & -\left\{d\left(u_{1}, x_{2}\right)+d\left(u_{2}, x_{1}\right)\right\} \\
& =3\left(x_{1}-x_{2}\right)-\left\{x_{1}+x_{2}-7+x_{1}+x_{2}-7\right\} \\
& =3 x_{1}-3 x_{2}-2 x_{1}-2 x_{2}+14=x_{1}-5 x_{2}+14 \\
& \leq 5-20+14=-1<0
\end{aligned}
$$

which gives

$$
d\left(u_{1}, u_{2}\right) \leq \frac{1}{3}\left\{d\left(u_{1}, x_{2}\right)+d\left(u_{2}, x_{1}\right)\right\}
$$

that is

$$
d\left(u_{1}, u_{2}\right) \leq f\left(d\left(x_{1}, x_{2}\right), d\left(u_{1}, x_{2}\right), d\left(u_{2}, x_{1}\right)\right) .
$$

Case 3: Let $x_{1} \in[3,4]$ and $x_{2} \in[4,5]$. Then as in the above cases, we have $u_{1}=3$ and $u_{2}+x_{2}=7$. Therefore,

$$
d\left(u_{1}, u_{2}\right)=\left|u_{1}-u_{2}\right|=\left|3-u_{2}\right|=u_{2}-3=4-x_{2} .
$$

Now,

$$
\begin{aligned}
d\left(u_{1}, x_{2}\right) & +d\left(u_{2}, x_{1}\right)=\left|3-x_{2}\right|+\left|u_{2}-x_{1}\right| \\
& =x_{2}-3+x_{1}+x_{2}-7=x_{1}+2 x_{2}-10 .
\end{aligned}
$$

Therefore, as in case- 2 , it can be shown that

$$
d\left(u_{1}, u_{2}\right) \leq f\left(d\left(x_{1}, x_{2}\right), d\left(u_{1}, x_{2}\right), d\left(u_{2}, x_{1}\right)\right) .
$$

Hence combining all the cases, we see that $S$ is a proximal $\mathcal{A}^{\prime}$-contraction of first kind. Hence Theorem 2 ensures that $S$ admits a unique best proximity point. Note that the best proximity point is 3 .

Next, we give the definitions of proximal $\mathcal{A}, \mathcal{A}^{\prime}$ - contractions of the second kind.

Definition 3. A mapping $S: G \rightarrow H$ is said to be a

(i) proximal $\mathcal{A}$-contraction of the second kind if there exists an $f \in \mathcal{A}$ satisfying

$$
\begin{aligned}
& d\left(u_{1}, S x_{1}\right)=\operatorname{dist}(G, H) \\
& \left.d\left(u_{2}, S x_{2}\right)=\operatorname{dist}(G, H)\right\} \\
& \Longrightarrow d\left(S u_{1}, S u_{2}\right) \leq f\left(d\left(S x_{1}, S x_{2}\right), d\left(S u_{1}, S x_{1}\right), d\left(S u_{2}, S x_{2}\right)\right)
\end{aligned}
$$

for all $u_{1}, u_{2}, x_{1}, x_{2} \in G$, 
(ii) proximal $\mathcal{A}^{\prime}$-contraction of the second kind if there exists an $f \in \mathcal{A}^{\prime}$ satisfying

$$
\begin{aligned}
& d\left(u_{1}, S x_{1}\right)=\operatorname{dist}(G, H) \\
& \left.d\left(u_{2}, S x_{2}\right)=\operatorname{dist}(G, H)\right\} \\
& \Longrightarrow d\left(S u_{1}, S u_{2}\right) \leq f\left(d\left(S x_{1}, S x_{2}\right), d\left(S u_{1}, S x_{2}\right), d\left(S u_{2}, S x_{1}\right)\right)
\end{aligned}
$$

for all $u_{1}, u_{2}, x_{1}, x_{2} \in G$.

Our upcoming two results deal with the existence of best proximity point(s) of the aforementioned contractions. Before presenting these results, we first recall the following definition:

Definition 4. ([17, p. 1774, Definition 2.1]). $G$ is said to be approximatively compact with respect to $H$ if every sequence $\left\{x_{n}\right\}$ in $G$ with $d\left(y, x_{n}\right) \rightarrow d(y, G)$ for some $y$ in $H$, has a convergent subsequence in $G$.

Theorem 3. Suppose that $(M, d)$ is complete, $G, H$ are closed, $G$ is approximately compact with respect to $H$ and $G_{0} \neq \varnothing$. Let $S: G \rightarrow H$ be a continuous proximal $\mathcal{A}$-contraction of the second kind such that $S\left(G_{0}\right)$ resides in $H_{0}$. Then $S$ has a best proximity point in $G$. Moreover, if $S$ is injective, then the best proximity point is unique.

Proof. Since $G_{0}$ is non-empty, we choose an element $v_{0} \in G$. Then $S v_{0} \in S\left(G_{0}\right) \subset$ $H_{0}$. Then there is an element $v_{1} \in G_{0}$ such that $d\left(v_{1}, S v_{0}\right)=\operatorname{dist}(G, H)$. Similarly, $S v_{1} \in H_{0}$ and in the same way we find an element $v_{2} \in G_{0}$ such that $d\left(v_{2}, S v_{1}\right)=$ $\operatorname{dist}(G, H)$. Therefore, continuing this process we arrive at a sequence $\left\{v_{n}\right\}$ of elements of $G_{0}$ such that

$$
d\left(v_{n+1}, S v_{n}\right)=\operatorname{dist}(G, H) \text { for all } n \in \mathbb{N} .
$$

Now note that

and

$$
d\left(v_{n}, S v_{n-1}\right)=\operatorname{dist}(G, H)
$$

$$
d\left(v_{n+1}, S v_{n}\right)=\operatorname{dist}(G, H)
$$

for all $n \in \mathbb{N}$. Since $S$ is a proximal $\mathcal{A}$-contraction of the second kind, there exists an $f \in \mathcal{A}$ such that

$$
d\left(S v_{n}, S v_{n+1}\right) \leq f\left(d\left(S v_{n-1}, S v_{n}\right), d\left(S v_{n}, S v_{n-1}\right), d\left(S v_{n+1}, S v_{n}\right)\right) .
$$

So there exists a $k \in[0,1)$ such that

$$
d\left(S v_{n}, S v_{n+1}\right) \leq k d\left(S v_{n-1}, S v_{n}\right)
$$

for all $n \in \mathbb{N}$ which, in fact, implies that

$$
d\left(S v_{n}, S v_{n+1}\right) \leq k^{n} d\left(S v_{1}, S v_{0}\right) .
$$

Now for any $m, n \in \mathbb{N}$, we have

$$
d\left(S v_{m+n}, S v_{n}\right) \leq d\left(S v_{m+n}, S v_{m+n-1}\right)+d\left(S v_{m+n-1}, S v_{m+n-2}\right)+\cdots+d\left(S v_{n+1}, S v_{n}\right)
$$




$$
\begin{aligned}
& \leq\left(k^{m+n-1}+k^{m+n-2}+\cdots+k^{n}\right) d\left(S v_{1}, S v_{0}\right) \\
& =k^{n} \frac{1-k^{m}}{1-k} d\left(S v_{1}, S v_{0}\right) \longrightarrow 0 \text { as } m, n \rightarrow \infty .
\end{aligned}
$$

This shows that $\left\{S v_{n}\right\}$ is a Cauchy sequence in $H$. Now closedness of $H$ in the complete metric space $(M, d)$ ensures the existence of an element $v \in H$ such that $S v_{n} \longrightarrow v$ as $n \rightarrow \infty$. Now,

$$
\begin{aligned}
\operatorname{dist}(v, G) & \leq d\left(v, v_{n}\right) \leq d\left(v, S v_{n-1}\right)+d\left(S v_{n-1}, v_{n}\right) \\
& =d\left(v, S v_{n-1}\right)+\operatorname{dist}(G, H) \leq d\left(v, S v_{n-1}\right)+\operatorname{dist}(v, G)
\end{aligned}
$$

which implies that $d\left(v, v_{n}\right) \rightarrow \operatorname{dist}(v, G)$ as $n \rightarrow \infty$. Since $G$ is proximally compact with respect to $H,\left\{v_{n}\right\}$ has a convergent subsequence $\left\{v_{n_{k}}\right\}$ in $G$. Let $v_{n_{k}} \rightarrow u$ for some $u \in G$. Then

$$
d(u, v)=\lim _{k \rightarrow \infty} d\left(v_{n_{k}}, S v_{n_{k}-1}\right)=\operatorname{dist}(G, H) .
$$

Therefore, $u \in G_{0}$. Since $S$ is continuous, $S v_{n_{k}} \rightarrow S u$ as $k \rightarrow \infty$. Again we have, $S v_{n_{k}} \rightarrow v$ as $k \rightarrow \infty$. Hence $v=S u$. Thus, $d(u, S u)=\operatorname{dist}(G, H)$.

Finally, let $S$ be injective. Let $u^{*}$ be another element in $G$ such that $d\left(u^{*}, S u^{*}\right)=$ $\operatorname{dist}(G, H)$. Then,

$$
d\left(\mathrm{Su}, \mathrm{Su} u^{*}\right) \leq f\left(d\left(\mathrm{Su}, \mathrm{Su} u^{*}\right), d(\mathrm{Su}, \mathrm{Su}), d\left(\mathrm{Su}^{*}, \mathrm{Su} u^{*}\right)\right)=f\left(d\left(\mathrm{Su}, \mathrm{Su} u^{*}\right), 0,0\right)
$$

which implies that

$$
d\left(S u, S u^{*}\right) \leq k \cdot 0=0 .
$$

Hence $S u=S u^{*}$. Since $S$ is injective, we have $u=u^{*}$ and the proof is complete.

Theorem 4. Suppose that $(M, d)$ is complete, $G, H$ are closed, $G$ is approximately compact with respect to $H$ and $G_{0} \neq \varnothing$. Let $S: G \rightarrow H$ be a continuous proximal $\mathcal{A}^{\prime}$-contraction of the second kind such that $S\left(G_{0}\right)$ resides in $H_{0}$. Then $S$ has a best proximity point in $G$. Moreover, if $S$ is injective, then the best proximity point is unique.

Proof. Proceeding as in Theorem 3, we can construct a sequence $\left\{v_{n}\right\}$ of elements of $G_{0}$ such that

$$
d\left(v_{n+1}, S v_{n}\right)=\operatorname{dist}(G, H) \text { for all } n \in \mathbb{N} .
$$

Now note that

$$
d\left(v_{n}, S v_{n-1}\right)=\operatorname{dist}(G, H)
$$

and

$$
d\left(v_{n+1}, S v_{n}\right)=\operatorname{dist}(G, H)
$$

for all $n \in \mathbb{N}$. Since $S$ is a proximal $\mathcal{A}^{\prime}$-contraction of the second kind, there exists an $f \in \mathcal{A}^{\prime}$ such that

$$
\begin{aligned}
d\left(S v_{n}, S v_{n+1}\right) & \leq f\left(d\left(S v_{n-1}, S v_{n}\right), d\left(S v_{n}, S v_{n}\right), d\left(S v_{n+1}, S v_{n-1}\right)\right) \\
& \leq f\left(d\left(S v_{n-1}, S v_{n}\right), 0, d\left(S v_{n+1}, S v_{n}\right)+d\left(S v_{n}, S v_{n-1}\right)\right)
\end{aligned}
$$


So there exists a $k \in[0,1)$ such that

$$
d\left(S v_{n}, S v_{n+1}\right) \leq k d\left(S v_{n-1}, S v_{n}\right)
$$

for all $n \in \mathbb{N}$. Following similar arguments, as in Theorem 3, we can prove that $\left\{S v_{n}\right\}$ is a Cauchy sequence in $H$. Since $H$ is a closed subset of the complete metric space $(M, d)$, we get an element $v \in H$ such that $S v_{n} \longrightarrow v$ as $n \rightarrow \infty$. Now,

$$
\begin{aligned}
\operatorname{dist}(v, G) & \leq d\left(v, v_{n}\right) \leq d\left(v, S v_{n-1}\right)+d\left(S v_{n-1}, v_{n}\right) \\
& =d\left(v, S v_{n-1}\right)+\operatorname{dist}(G, H) \leq d\left(v, S v_{n-1}\right)+\operatorname{dist}(v, G)
\end{aligned}
$$

which implies that $d\left(v, v_{n}\right) \rightarrow \operatorname{dist}(v, G)$ as $n \rightarrow \infty$. Since $G$ is proximally compact with respect to $H,\left\{v_{n}\right\}$ has a convergent subsequence $\left\{v_{n_{k}}\right\}$ in $G$. Let $v_{n_{k}} \rightarrow u$ for some $u \in G$. Now

$$
d(u, v)=\lim _{k \rightarrow \infty} d\left(v_{n_{k}}, S v_{n_{k}-1}\right)=\operatorname{dist}(G, H) .
$$

This implies that $u \in G_{0}$. Applying continuity of $S$, we get $S v_{n_{k}} \rightarrow S u$ as $k \rightarrow \infty$. Again we have, $S v_{n_{k}} \rightarrow v$ as $k \rightarrow \infty$. Hence $v=S u$. Thus, $d(u, S u)=\operatorname{dist}(G, H)$.

We now take $S$ to be injective. Let $u^{*}$ be another element in $G$ such that $d\left(u^{*}, S u^{*}\right)=$ $\operatorname{dist}(G, H)$. Then,

$$
d\left(\mathrm{Su}, \mathrm{Su} u^{*}\right) \leq f\left(d\left(\mathrm{Su}, \mathrm{Su} u^{*}\right), d\left(\mathrm{Su}, \mathrm{Su} u^{*}\right), d\left(\mathrm{Su}^{*}, \mathrm{Su}\right)\right)
$$

which implies that

$$
d\left(S u, S u^{*}\right)=0 .
$$

Hence $S u=S u^{*}$. Since $S$ is injective, we have $u=u^{*}$ and the proof is complete.

Remark 1. In the above two theorems, to ensure the uniqueness of best proximity point, injectiveness of $S$ is not necessary, which follows from the following examples.

Example 4. We take $(M, d)=\left(\mathbb{R}^{2}, d\right)$ where

$$
d\left(\left(x_{1}, y_{1}\right),\left(x_{2}, y_{2}\right)\right)=\left|x_{1}-x_{2}\right|+\left|y_{1}-y_{2}\right|
$$

for all $\left(x_{1}, y_{1}\right),\left(x_{2}, y_{2}\right) \in \mathbb{R}^{2}$;

$$
\begin{aligned}
G & =\left\{(x, y) \in \mathbb{R}^{2}: 4 \leq x \leq 5,0 \leq y \leq 1\right\}, \\
H & =\left\{(x, y) \in \mathbb{R}^{2}: 0 \leq x \leq 1,0 \leq y \leq 1\right\} ; \\
f(r, s, t) & =\frac{1}{2} r+\frac{1}{5}(s+t),
\end{aligned}
$$

and define $S: G \rightarrow H$ by

$$
S(x, y)=\left(1, \frac{y}{2}\right)
$$

for all $(x, y) \in G$. Let $u_{1}=\left(u_{1}^{\prime}, u_{1}^{\prime \prime}\right), u_{2}=\left(u_{2}^{\prime}, u_{2}^{\prime \prime}\right), x_{1}=\left(x_{1}^{\prime}, x_{1}^{\prime \prime}\right), x_{2}=\left(x_{2}^{\prime}, x_{2}^{\prime \prime}\right) \in G$ be such that

$$
d\left(u_{1}, S x_{1}\right)=\operatorname{dist}(G, H)=3 \text { and } d\left(u_{2}, S x_{2}\right)=\operatorname{dist}(G, H)=3 .
$$


Then, $S x_{1}=\left(1, \frac{x_{1}^{\prime \prime}}{2}\right)$ and $S x_{2}=\left(1, \frac{x_{2}^{\prime \prime}}{2}\right)$. Now,

$$
\begin{aligned}
& d\left(u_{1}, S x_{1}\right)=3 \\
& \Longrightarrow d\left(\left(u_{1}^{\prime}, u_{1}^{\prime \prime}\right),\left(1, \frac{x_{1}^{\prime \prime}}{2}\right)\right)=3 \\
& \Longrightarrow\left|u_{1}^{\prime}-1\right|+\left|u_{1}^{\prime \prime}-\frac{x_{1}^{\prime \prime}}{2}\right|=3 \\
& \Longrightarrow u_{1}^{\prime}-1+\left|u_{1}^{\prime \prime}-\frac{x_{1}^{\prime \prime}}{2}\right|=3 \\
& \Longrightarrow u_{1}^{\prime}+\left|u_{1}^{\prime \prime}-\frac{x_{1}^{\prime \prime}}{2}\right|=4
\end{aligned}
$$

which implies that $u_{1}^{\prime}=4$ and $u_{1}^{\prime \prime}=\frac{x_{1}^{\prime \prime}}{2}$. Similarly, $d\left(u_{2}, S x_{2}\right)=3$ gives $u_{2}^{\prime}=4$ and $u_{2}^{\prime \prime}=\frac{x_{2}^{\prime \prime}}{2}$. Therefore,

$$
\begin{aligned}
d\left(S u_{1}, S u_{2}\right) & =d\left(\left(1, \frac{u_{1}^{\prime \prime}}{2}\right),\left(1, \frac{u_{2}^{\prime \prime}}{2}\right)\right) \\
& =\left|\frac{u_{1}^{\prime \prime}}{2}-\frac{u_{2}^{\prime \prime}}{2}\right|=\left|\frac{x_{1}^{\prime \prime}}{4}-\frac{x_{2}^{\prime \prime}}{4}\right|=\frac{1}{4}\left|x_{1}^{\prime \prime}-x_{2}^{\prime \prime}\right| .
\end{aligned}
$$

Also,

$$
d\left(S x_{1}, S x_{2}\right)=d\left(\left(1, \frac{x_{1}^{\prime \prime}}{2}\right),\left(1, \frac{\left.x_{2}^{\prime \prime}\right)}{2}\right)\right)=\frac{1}{2}\left|x_{1}^{\prime \prime}-x_{2}^{\prime \prime}\right|
$$

Now,

$$
\begin{aligned}
d\left(S u_{1}, S u_{2}\right)-f\left(d\left(S x_{1}, S x_{2}\right), d\left(S u_{1}, S x_{1}\right), d\left(S u_{2}, S x_{2}\right)\right) & \\
= & d\left(S u_{1}, S u_{2}\right)-\left\{\frac{1}{2} d\left(S x_{1}, S x_{2}\right)+\frac{1}{5}\left(d\left(S u_{1}, S x_{1}\right)+d\left(S u_{2}, S x_{2}\right)\right)\right\} \\
= & \frac{1}{4}\left|x_{1}^{\prime \prime}-x_{2}^{\prime \prime}\right|-\frac{1}{4}\left|x_{1}^{\prime \prime}-x_{2}^{\prime \prime}\right|-\frac{1}{5}\left(d\left(S u_{1}, S x_{1}\right)+d\left(S u_{2}, S x_{2}\right)\right) \leq 0
\end{aligned}
$$

which yields that

$$
d\left(S u_{1}, S u_{2}\right) \leq f\left(d\left(S x_{1}, S x_{2}\right), d\left(S u_{1}, S x_{1}\right), d\left(S u_{2}, S x_{2}\right)\right)
$$

which, in turn, implies that $S$ is a proximal $\mathcal{A}$-contraction of the second kind. It is easy to check that $(4,0)$ is the unique best proximity point of $S$ and $S$ is not injective.

Example 5. In this example, we take the metric space $(M, d)$ as above and choose

$$
G=\left\{(x, y) \in \mathbb{R}^{2}: x=2,0 \leq y \leq 3\right\} \bigcup\left\{(x, y) \in \mathbb{R}^{2}: 0 \leq x \leq 2, y=2\right\}
$$

and

$$
H=\left\{(x, y) \in \mathbb{R}^{2}: 0 \leq x \leq 1,0 \leq y \leq 1\right\} .
$$


Then $\operatorname{dist}(G, H)=1$. We define $S: G \rightarrow H$ by

$$
S(x, y)=\left(\frac{x}{2}, 0\right)
$$

for all $(x, y) \in G$. Also we choose $f \in \mathcal{A}^{\prime}$ which is defined by $f(r, s, t)=\frac{1}{4}(s+t)$. Let $u_{1}, u_{2}, x_{1}, x_{2} \in G$ be such that $d\left(u_{1}, S x_{1}\right)=\operatorname{dist}(G, H)=d\left(u_{2}, S x_{2}\right)$. Then we have

$$
\begin{aligned}
& d\left(\left(u_{1}^{\prime}, u_{1}^{\prime \prime}\right),\left(\frac{x_{1}^{\prime}}{2}, 0\right)\right)=1 \\
& \Longrightarrow\left|u_{1}^{\prime}-\frac{x_{1}^{\prime}}{2}\right|+\left|u_{1}^{\prime \prime}\right|=1
\end{aligned}
$$

which implies that $u_{1}^{\prime \prime} \leq 1$ and $u_{1}^{\prime}=2$. Similarly, we get $u_{2}^{\prime \prime} \leq 1$ and $u_{2}^{\prime}=2$. Now,

$$
d\left(S u_{1}, S u_{2}\right)=d\left(\left(\frac{u_{1}^{\prime}}{2}, 0\right),\left(\frac{u_{2}^{\prime}}{2}, 0\right)\right)=\left|\frac{u_{1}^{\prime}}{2}-\frac{u_{2}^{\prime}}{2}\right|=0 .
$$

Therefore,

$$
d\left(S u_{1}, S u_{2}\right) \leq f\left(d\left(S x_{1}, S x_{2}\right), d\left(S x_{1}, u_{2}\right), d\left(S x_{2}, u_{1}\right)\right)
$$

whence $S$ is a proximal $\mathcal{A}^{\prime}$-contraction of second kind. One can easily verify that $(4,0)$ is the unique best proximity point of $S$ and $S$ is not injective.

Remark 2. In Theorem 3 and Theorem 4, the injectiveness of $S$ can't be dropped, which follows from the following example.

Example 6. Let us take $M=\mathbb{R}, d$ as the usual metric and $G=\left[-1,-\frac{1}{2}\right] \cup\left[\frac{1}{2},-1\right]$, $H=\{0\}$. We define $S: G \rightarrow H$ by $S x=0$ for all $x \in G$. Then one can check that $S$ is proximal $\mathcal{A}, \mathcal{A}^{\prime}$-contractions of the second kind and $S$ has two best proximity points viz., $-\frac{1}{2}, \frac{1}{2}$. It may be noted that $S$ is not an injection.

Next, we come up with the notions of strong proximal contractions, and present two results exhibiting the sufficient conditions in order to get best proximity points of strong proximal contractions.

Definition 5. A mapping $S: G \rightarrow H$ is said to be

(i) a strong proximal $\mathcal{A}$-contraction if there exists an $f \in \mathcal{A}$ such that for all $u_{1}, u_{2}, x_{1}, x_{2} \in G$ and for all $\gamma \in[1,2)$

$$
\begin{aligned}
& d\left(u_{1}, S x_{1}\right) \leq \gamma \operatorname{dist}(G, H) \\
& \left.d\left(u_{2}, S x_{2}\right) \leq \gamma \operatorname{dist}(G, H)\right\} \\
& \Longrightarrow d\left(u_{1}, u_{2}\right) \leq f\left(d\left(x_{1}, x_{2}\right), d\left(u_{1}, x_{1}\right), d\left(u_{2}, x_{2}\right)\right)+(\gamma-1) \operatorname{dist}(G, H) \text {, }
\end{aligned}
$$

(ii) a strong proximal $\mathcal{A}^{\prime}$-contraction if there exists an $f \in \mathcal{A}^{\prime}$ such that for all $u_{1}, u_{2}, x_{1}, x_{2} \in G$ and for all $\gamma \in[1,2)$

$$
\begin{aligned}
& d\left(u_{1}, S x_{1}\right) \leq \gamma \operatorname{dist}(G, H) \\
& \left.d\left(u_{2}, S x_{2}\right) \leq \gamma \operatorname{dist}(G, H)\right\} \\
& \Longrightarrow d\left(u_{1}, u_{2}\right) \leq f\left(d\left(x_{1}, x_{2}\right), d\left(u_{1}, x_{2}\right), d\left(u_{2}, x_{1}\right)\right)+(\gamma-1) \operatorname{dist}(G, H) \text {. }
\end{aligned}
$$


Theorem 5. Suppose that $(M, d)$ is complete, $G, H$ are closed and dist $(G, H)>0$. Let $S: G \rightarrow H$ be a continuous strong proximal $\mathcal{A}$-contraction such that there exists a sequence $\left\{x_{n}\right\}$ in $G$ with $d\left(x_{n}, S x_{n}\right) \rightarrow \operatorname{dist}(G, H)$ as $n \rightarrow \infty$. Then $S$ has a unique best proximity point and $\left\{x_{n}\right\}$ has a subsequence converging to that best proximity point.

Proof. For each $p \in \mathbb{N}$, we define

$$
F_{p}=\left\{x \in G: d(x, S x) \leq\left(1+\frac{1}{p}\right) \operatorname{dist}(G, H)\right\} .
$$

Since $d\left(x_{n}, S x_{n}\right) \rightarrow \operatorname{dist}(G, H)$, there exists an $n_{p} \in \mathbb{N}$ such that

$$
d\left(x_{n_{p}}, S x_{n_{p}}\right) \leq\left(1+\frac{1}{p}\right) \operatorname{dist}(G, H)
$$

which implies that $F_{p}$ is non-empty for each $p \in \mathbb{N}$. Since $S$ is continuous, each $F_{p}$ is closed. It is also evident that $F_{p+1} \subset F_{p}$ for each $p \in \mathbb{N}$. If $x$ and $x^{*}$ are two elements of $F_{p}$, then we have

$$
d(x, S x) \leq\left(1+\frac{1}{p}\right) \operatorname{dist}(G, H)
$$

and

$$
d\left(x^{*}, S x^{*}\right) \leq\left(1+\frac{1}{p}\right) \operatorname{dist}(G, H)
$$

Since $S$ is a strong proximal $\mathcal{A}$-contraction, there exists $f \in \mathcal{A}$ such that

$$
\begin{aligned}
d\left(x, x^{*}\right) & \leq f\left(d\left(x, x^{*}\right), d(x, x), d\left(x^{*}, x^{*}\right)\right)+\frac{1}{p} \operatorname{dist}(G, H) \\
& =f\left(d\left(x, x^{*}\right), 0,0\right)+\frac{1}{p} \operatorname{dist}(G, H) \\
& \leq \alpha d\left(x, x^{*}\right)+\frac{1}{p} \operatorname{dist}(G, H) \text { for some } \alpha \in[0,1) .
\end{aligned}
$$

Therefore, we get

$$
d\left(x, x^{*}\right) \leq \frac{1}{(1-\alpha) p} \operatorname{dist}(G, H) .
$$

Hence $\operatorname{diam}\left(A_{p}\right) \rightarrow 0$ as $p \rightarrow \infty$. Therefore by Cantor's intersection theorem, we have

$$
\bigcap_{p} F_{p}=\{u\}
$$

for some $u \in G$. From this we see that,

$$
\operatorname{dist}(G, H) \leq d(u, S u) \leq\left(1+\frac{1}{p}\right) \operatorname{dist}(G, H)
$$

for each $p$. Hence we have

$$
d(u, S u)=\operatorname{dist}(G, H) .
$$


For the last part, it is to be noted that

$$
d\left(x_{n_{p}}, u\right) \leq \frac{1}{(1-\alpha) p} \operatorname{dist}(G, H) .
$$

Hence the subsequence $\left\{x_{n_{p}}\right\}$ converges to $u$ and the theorem follows.

Remark 3. The conclusions of the above theorem also hold if $S$ is a strong proximal $\mathcal{A}^{\prime}$-contraction instead of strong proximal $\mathcal{A}$-contraction. The proof being similar to the above theorem, we omit it.

We conclude this paper by presenting an example in support of Theorem 5 followed by a couple of remarks.

Example 7. Let us take $(M, d)=(\mathbb{R}, d), d$ being the usual metric; $G=[0,1]$ and $H=[5,6]$ and take $f \in \mathcal{A}$, where $f(r, s, t)=\frac{1}{4}(r+s+t)$. We define $S: G \rightarrow H$ by $S x=6-x$ for all $x \in G$.

Let $u_{1}, u_{2}, x_{1}, x_{2} \in G$ be such that $d\left(u_{1}, S x_{1}\right) \leq \gamma \operatorname{dist}(G, H)$ and $d\left(u_{2}, S x_{2}\right) \leq \gamma \operatorname{dist}(G, H)$ for all $\gamma \in[1,2]$. Then

$$
\begin{aligned}
\left|u_{1}-S x_{1}\right| \leq 4 \gamma & \Longrightarrow\left|u_{1}-6+x_{1}\right| \leq 4 \gamma \\
& \Longrightarrow 6-u_{1}-x_{1} \leq 4 \gamma \\
& \Longrightarrow u_{1} \geq 6-4 \gamma-x_{1}
\end{aligned}
$$

Similarly,

$$
u_{2} \geq 6-4 \gamma-x_{2}
$$

Without loss of generality, we assume that $u_{1} \geq u_{2}$. Therefore,

$$
\begin{aligned}
d\left(u_{1}, u_{2}\right) & =\left|u_{1}-u_{2}\right|=u_{1}-u_{2} \leq u_{1}-\left(6-4 \gamma-x_{2}\right) \\
& =u_{1}-6+4 \gamma+x_{2} \leq 1+1-6+4 \gamma=4(\gamma-1)=(\gamma-1) d(A, B) .
\end{aligned}
$$

So, we get

$$
d\left(u_{1}, u_{2}\right) \leq f\left(d\left(x_{1}, x_{2}\right), d\left(u_{1}, x_{1}\right), d\left(u_{2}, x_{2}\right)\right)+(\gamma-1) \operatorname{dist}(G, H)
$$

for any $f \in \mathcal{A}$ which implies that $S$ is a strong proximal $\mathcal{A}$-contraction. Consequently by Theorem $5, S$ has a unique best proximity point. Also, the unique best proximity point is 1 .

Remark 4. The best proximity point results of different kinds of proximal contractions due to Sadiq Basha [17] can be obtained from our results by choosing $f(r, s, t)=\alpha r$, where $\alpha \in[0,1)$.

Remark 5. By selecting different $f$ in Theorem 1, Theorem 3 and Theorem 5, we can obtain the best proximity point results of the proximal versions of the contractions of Kannan [8] $\left(f(r, s, t)=\alpha(s+t)\right.$, where $\left.0 \leq \alpha<\frac{1}{2}\right)$, Reich [16] $\left(f(r, s, t)=\alpha_{1} r+\right.$ $\alpha_{2} s+\alpha_{3} t$, where $\left.0 \leq \alpha_{1}, \alpha_{2}, \alpha_{3}<1 ; \alpha_{1}+\alpha_{2}+\alpha_{3}<1\right)$, Bianchini [5] $(f(r, s, t)=$ $\alpha \max \{s, t\}$, where $0 \leq \alpha<1)$ and Khan [10] $(f(r, s, t)=\alpha \sqrt{s t}$, where $0 \leq \alpha<1)$. 
Remark 6. In this remark, we point out some suitable areas where our obtained results can be utilized. In many cases of sciences and engineering, instead of solutions of certain kinds of integro-differential equations, one need optimal solutions of the same. On the other hand, if an integral or differential equation does not possess any solution, then we often show interest on the best proximity solutions of the equation (see [21], [6]). In the aforementioned two cases, the desired optimal and best proximity solutions can be dealt by best proximity point results only. Thus in such cases, our obtained best proximity point results can be applied.

\section{ACKNOWLEDGEMENT}

The authors gratefully acknowledge the valuable comments and suggestions of the editor and the anonymous referee, which help them to prepare the revised version of the manuscript in the present form.

\section{REFERENCES}

[1] M. Akram, A. A. Zafar, and A. A. Siddiqui, "A general class of contractions: A-contractions," Novi Sad J. Math., vol. 38, no. 1, pp. 25-33, 2008.

[2] M. A. Al-Thagafi and N. Shahzad, "Best proximity pairs and equilibrium pairs for Kakutani multimaps," Nonlinear Anal., vol. 70, no. 3, pp. 1209-1216, 2009, doi: 10.1016/j.na.2008.07.022.

[3] J. Anuradha and P. Veeramani, "Proximal pointwise contraction," Topology Appl., vol. 156, no. 18, pp. 2942-2948, 2009.

[4] P. Ardsalee and S. Saejung, "Some common best proximity point theorems via a fixed point theorem in metric spaces," Fixed Point Theory, vol. 21, no. 2, pp. 413-426, 2020, doi: 10.24193/fptro.2020.2.29.

[5] R. M. T. Bianchini, "Su un problema di S. Reich riguardante la teoria dei punti fissi," Boll. Un. Mat. Ital., vol. 5, pp. 103-108, 1972.

[6] M. Gabeleh and C. Vetro, "A best proximity point approach to existence of solutions for a system of ordinary differential equations," Bull. Belg. Math. Soc. Simon Stevin, vol. 26, no. 4, pp. 493503, 2019, doi: 10.36045/bbms/1576206350.

[7] H. Garai, L. K. Dey, and Y. J. Cho, "On contractive mappings and discontinuity at fixed points," Appl. Anal. Discrete Math., vol. 14, no. 1, pp. 033-054, 2020, doi: 10.2298/AADM181018007G.

[8] R. Kannan, "Some results on fixed points," Bull. Calcutta Math. Soc., vol. 60, pp. 71-76, 1968.

[9] E. Karapınar, "Best proximity points of cyclic mappings," Appl. Math. Lett., vol. 25, no. 11, pp. 1761-1766, 2012.

[10] M. S. Khan, “On fixed point theorems," Math. Japonica, vol. 23, no. 2, pp. 201-204, 1978/79.

[11] W. K. Kim, S. Kum, and K. H. Lee, "On general best proximity pairs and equilibrium pairs in free abstract economies," Nonlinear Anal., vol. 68, no. 8, pp. 2216-2227, 2008, doi: 10.1016/j.na.2007.01.057.

[12] W. A. Kirk, S. Reich, and P. Veeramani, "Proximinal retracts and best proximity pair theorems," Numer. Funct. Anal. Optim., vol. 24, pp. 851-862, 2003, doi: 10.1081/NFA-120026380.

[13] A. Kostić, V. Rakǒcević, and S. Radenović, "Best proximity points involving simulation functions with $w_{0}$-distance," Rev. R. Acad. Cienc. Exactas Fis. Nat. Ser. A Mat. RACSAM, vol. 113, no. 2, pp. 715-727, 2019, doi: 10.1007/s13398-018-0512-1.

[14] P. Mondal, H. Garai, and L. K. Dey, "On some enriched contractions in Banach spaces," arXiv:2006.11500. 
[15] S. Mondal and L. K. Dey, "Some common best proximity point theorems in a complete metric space," Afr. Mat., vol. 28, p. 85-97, 2017, doi: 10.1007/s13370-016-0432-1.

[16] S. Reich, "Some remarks concerning contraction mappings," Canad. Math. Bull., vol. 14, no. 1, pp. 121-124, 1971.

[17] S. Sadiq Basha, "Best proximity point theorems," J. Approx. Theory, vol. 163, no. 11, pp. 17721781, 2011, doi: 10.1016/j.jat.2011.06.012.

[18] S. Sadiq Basha, "Best proximity points: optimal solutions," J. Optim. Theory Appl., vol. 151, no. 1, pp. 210-216, 2011, doi: 10.1007/s10957-011-9869-4.

[19] S. Sadiq Basha, "Best proximity point theorems for some special proximal contractions," Numer. Funct. Anal. Optim., vol. 40, no. 10, pp. 1182-1193, 2019, doi: 10.1080/01630563.2019.1598431.

[20] S. Sadiq Basha and P. Veeramani, "Best approximations and best proximity pairs," Acta Sci. Math. (Szeged), vol. 63, pp. 289-300, 1997.

[21] G. Sankara Raju Kosuru, "On best proximity pairs with application to differential equations," Fixed Point Theory, vol. 21, no. 2, pp. 647-656, 2020, doi: 10.24193/fpt-ro.2020.2.45.

[22] K. Włodarczyk, R. Plebaniak, and A. Banach, "Best proximity points for cyclic and noncyclic set-valued relatively quasi-asymptotic contractions in uniform spaces," Nonlinear Anal., vol. 70, no. 6, pp. 3332-3341, 2009, doi: 10.1016/j.na.2008.04.037.

Authors' addresses

Pratikshan Mondal

(Corresponding author) Department of Mathematics, Durgapur Government College, Durgapur, India

E-mail address: real.analysis77@gmail.com

\section{Hiranmoy Garai}

Department of Mathematics, National Institute of Technology Durgapur, India

Current address: Department of Science and Humanities, Siliguri Govt. Polytechnic, Siliguri, India

E-mail address: hiran.garai24@gmail.com

Lakshmi Kanta Dey

Department of Mathematics, National Institute of Technology Durgapur, India

E-mail address: lakshmikdey@yahoo.co.in 